\title{
Trails of meaning construction: Symbolic artifacts engage the social brain
}

\author{
Kristian Tylén a,b,c,* , Johanne Stege Philipsen ${ }^{\mathrm{a}, \mathrm{b}}$, Andreas Roepstorff ${ }^{\mathrm{b}, \mathrm{c}}$, Riccardo Fusaroli a,b,c \\ ${ }^{a}$ Center for Semiotics, School of Communication and Culture, Aarhus University, Denmark \\ b The Interacting Minds Centre, Aarhus University, Denmark \\ ${ }^{c}$ The Center for Functionally Integrative Neuroscience, Aarhus University Hospital, Denmark
}

\section{A R T I C L E I N F O}

\section{Article history:}

Received 6 January 2016

Accepted 21 March 2016

Available online 31 March 2016

\section{Keywords:}

Symbolic artifacts

Social cognition

MPFC

TPJ

IFG

\begin{abstract}
A B S T R A C T
Symbolic artifacts present a challenge to theories of neurocognitive processing due to their hybrid nature: they are at the same time physical objects and vehicles of intangible social meanings. While their physical properties can be read of their perceptual appearance, the meaning of symbolic artifacts depends on the perceiver's interpretative attitude and embeddedness in cultural practices. In this study, participants built models of LEGO bricks to illustrate their understanding of abstract concepts. They were then scanned with fMRI while presented to photographs of their own and others' models. When participants attended to the meaning of the models in contrast to their bare physical properties, we observed activations in MPFC and TPJ, areas often associated with social cognition, and IFG, possibly related to semantics. When contrasting own and others' models, we also found activations in precuneus, an area associated with autobiographical memory and agency, while looking at one's own collective models yielded interaction effects in rostral ACC, right IFG and left Insula. Interestingly, variability in the insula was predicted by individual differences in participants' feeling of relatedness to their fellow group members during LEGO construction activity. Our findings support a view of symbolic artifacts as neurocognitive trails of human social interactions.
\end{abstract}

(c) 2016 Elsevier Inc. All rights reserved.

\section{Introduction}

One of the great hallmarks of the human species is our profound engagement with material objects and technologies. Unlike even our closest primate relatives, we actively shape, explore and exploit our material surroundings to construct cultural and cognitive niches (Clark, 2006; Laland et al., 2000). While many material inventions consist in sophisticated tools for instrumental and pragmatic engagement of the environment, the broad class of symbolic artifacts does its work by virtue of meaning. Objects such as national flags, religious symbols, artworks, road signs, pictorial representations etc. are imbued with social significance as they are developed, negotiated and engaged in a variety of cultural practices. More than mere physical objects, we thus experience them as vehicles of social meaning: although a red traffic light does not present any physical impediment to movement, it still (most often) stops us from crossing the street. These pairings between physical forms and socially negotiated meanings are ubiquitous in human society and play a crucial role in structuring individual behaviors and social interactions (Latour, 1996, 2000; Roepstorff, 2008). Furthermore, novel form-meaning pairings are readily and flexibly established online in contexts of communication and coordination (Galantucci, 2005; Garrod et al., 2007), or pretense play (Leslie, 1987; Whitehead et al.,

\footnotetext{
* Corresponding author at: School of Communication and Culture, Jens Chr. Skous Vej 2, 8000 Aarhus, Denmark.

E-mail address: kristian@cc.au.dk (K. Tylén).
}

2009; Wyman et al., 2009), etc. This raises fundamental questions concerning the neuro-cognitive resources involved in appraising symbolic artifacts.

Previous brain-imaging studies have focused on the distinction between social versus non-social, or animate versus inanimate stimuli, and report dissociable networks of brain areas in reaction to these categories (Caramazza and Shelton, 1998; Gobbini et al., 2011; Naselaris et al., 2012). For instance the dorso-medial prefrontal cortex has been suggested to activate only when participants make judgments about other people and not objects (Jack et al., 2013; Mitchell et al., 2002, 2005). The assumption behind these studies is that stimuli come in ontologically pre-defined categories - for instance objects are non-social, while people are social - and patterns of functional brain activations are interpreted according to these pre-specified categories.

It has previously been found that experimental participants engage different networks of the social brain in response to questions of 'how?' and 'why?' when presented with the same social stimulus (such as an agent performing and action, Spunt and Adolphs, 2014; Spunt et al., 2010; Spunt and Lieberman, 2012, 2014; Spunt et al., 2011). In a similar vein, the double nature of symbolic artifacts potentially affords different modes of engagements: they are simultaneously physical entities and vehicles of non-tangible complex cultural meanings (Clark, 2006; Cussins, 1992; Hutchins, 2005), and this implies that they might give rise to distinctive patterns of functional brain activations according to how they are approached. Additionally, while their physical nature is easily appreciable, their social meaning is often not 
fully transparent to the casual newcomer but critically depends on participation in cultural practices and trajectories of actual use in social interactions (Hutchins, 2008; Tylén et al., 2013).

In this study we set out to investigate the neurocognitive bases of our engagements with cultural artifacts. In particular, we are interested in the extent to which our perception of such objects is affected by the functional context (what aspects of the object that are actualized in a given task or situation) and the social history in which the object is embedded. More specifically, we hypothesize that functional brain activation will be modulated by i) the interpretive attitude by which we approach the objects (as physical entities or as meaningful symbols), and ii) by our familiarity with the socio-cultural practices constituting the meaning of the objects. In other words, if socially symbolic dimensions are contextually actualized, we expect objects to evoke activity in the brain areas related to social cognition (such as e.g. mPFC and TPJ, Frith, 2007; Frith and Frith, 2006b; Lieberman, 2007; Tylén et al., 2012; Walter et al., 2004) and semantics (Hagoort, 2005; Jung-Beeman, 2005; Tylén et al., 2009). Furthermore, we expect this activity to be modulated by participation in the social history of the object (Mano et al., 2011). In contrast, if the bare physical properties of the same artifacts are profiled, we expect them to activate areas related to object recognition and manipulation, such as ventral temporal and motor areas (Bar et al., 2001; Binkofski et al., 1999).

To investigate these predictions we designed a two-part study in which participants were instructed to individually and collectively build objects out of LEGO bricks that would illustrate their understanding of abstract concepts. On the following day participants were shown pictures of LEGO models built by themselves or others while their brains were scanned with fMRI. In the scanner they were given assignments that primed them to perceive the LEGO constructs either as bare physical structures or as vehicles of socially constituted meaning.

\section{Materials and methods}

\section{Participants}

30 participants were recruited among students of Aarhus University and participated in the first part of the two-day experiment. Among these three dropped out at day two (before the fMRI experiment), while two participants were excluded due to technical problems during the imaging process. The remaining twenty-five participants (13 $\mathrm{f}$. mean age 24, sd 2.7) were all right-handed, native speakers of Danish, with no history of neurological or mental problems. Informed consent was obtained in a manner approved by the local research ethical committee. Participants received a monetary compensation for their participation.

\section{Design and procedure}

The experiment was carried out as a two-part study over two days. On the first day, participants were engaged in individual and collective LEGO construction activities. On the following day, participants went through an fMRI brain scan in which they were subjected to photographic stimuli depicting the products of the preceding day's individual and collective LEGO constructions.

\section{The LEGO construction activity}

The first day's LEGO construction activity was organized as a twocondition within-group contrast: collective vs. individual. Participants were organized in mixed-gender groups of four to six. Group members did not know each other in advance. Participants of each group were organized around a table facing each other (see Fig. 1). Two simpler practice trials served to familiarize them with each other and the LEGO materials. After that, groups underwent an interleaved series of six individual and six collective LEGO construction tasks of each five minutes. In the construction tasks, participants were instructed to use LEGO bricks

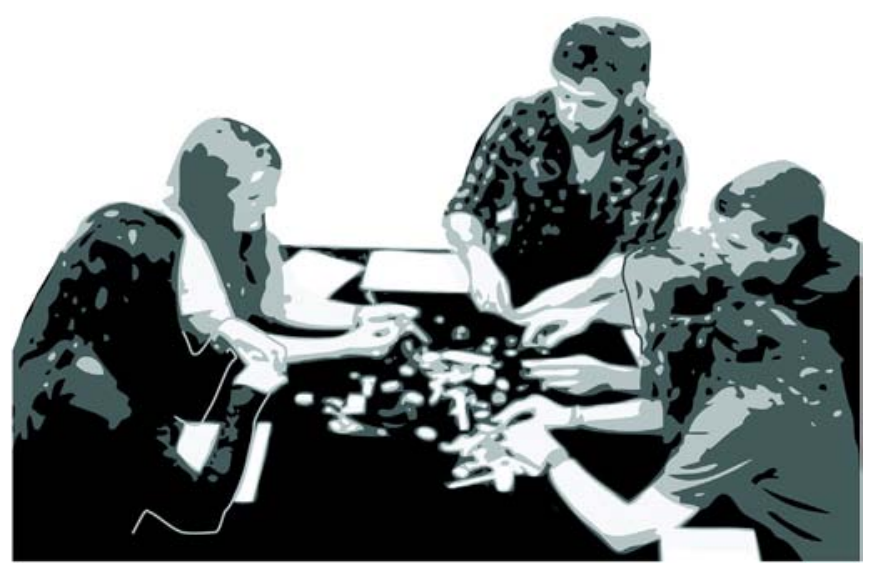

Fig. 1. Experimental setup for the LEGO construction activity. Group members were arranged around a table facing each other. In individual trials they each were given a fixed set of LEGO bricks and an A5 piece of cardboard on which to build their model. In collective trials group members shared one LEGO set and built their shared model on one piece of cardboard.

to illustrate their understanding of six abstract concepts: 'responsibility', 'collaboration', 'knowledge', 'justice', 'safety' and 'tolerance'. The concepts were selected to be challenging to build, yet sufficiently common in public discourse that participants would have an opinion about them. The LEGO materials were in all cases a LEGO Serious Play Starter Kit consisting of 214 mixed pieces (standards bricks in varying shapes and colors, wheels, LEGO people, etc.). In order to constrain variability in complexity and size of the models, participants were instructed to build their models within the limits of an A5 ( $5.8 \times 8.3$ in.) piece of cardboard (for examples of LEGO creations, see Fig. 2 ).

In individual trials, participants sat quietly and constructed their own models. In collective trials participants freely interacted to construct joint models. After each trial, participants were asked to briefly explain their model. The experiment was divided in two 3-concepts sessions separated by a 20 min break. Two video cameras consecutively recorded the construction activities and after each construction trial the resulting LEGO models were photographically documented with a Canon digital camera. The videos of the construction activities were analyzed with different purposes in other studies (Bjørndahl et al., 2014, 2015). By the end of the experiment, participants filled in the Intrinsic Motivation Inventory (Ryan, 1982) addressing their experience of the collaborative activity. In particular we were interested in the factors Relatedness and Group Competence, both of which capture central aspects of the quality of social interaction. Notice that since one participant did not fill in the questionnaire these analyses only have twenty-four observations.

\section{The fMRI study}

On the following day, participants came back to the lab individually for an fMRI brain scanning session. In the scanner, they were presented with photographic stimuli depicting LEGO models from the construction activities. These belonged to four conditions 1) models that the participant made with her group, 2) models that the participant made individually, 3) models made by another group, and 4) models made by another individual (from another group). Furthermore, each stimulus presentation would be accompanied by one of two rating tasks: a 'meaning property' and a 'physical property' tasks. The tasks were intended to modulate participants' attitude to the stimuli, inspecting the models for either their meaning potentials, which critically depended on their complex social histories, or their bare physical structure that did not - to the same extent - depend on memories of their creation. Together the conditions and tasks make up a 2-by-2-by-2 factorial design with the factors 'collective - individual', 'own - other' and 'meaning - physical'. 

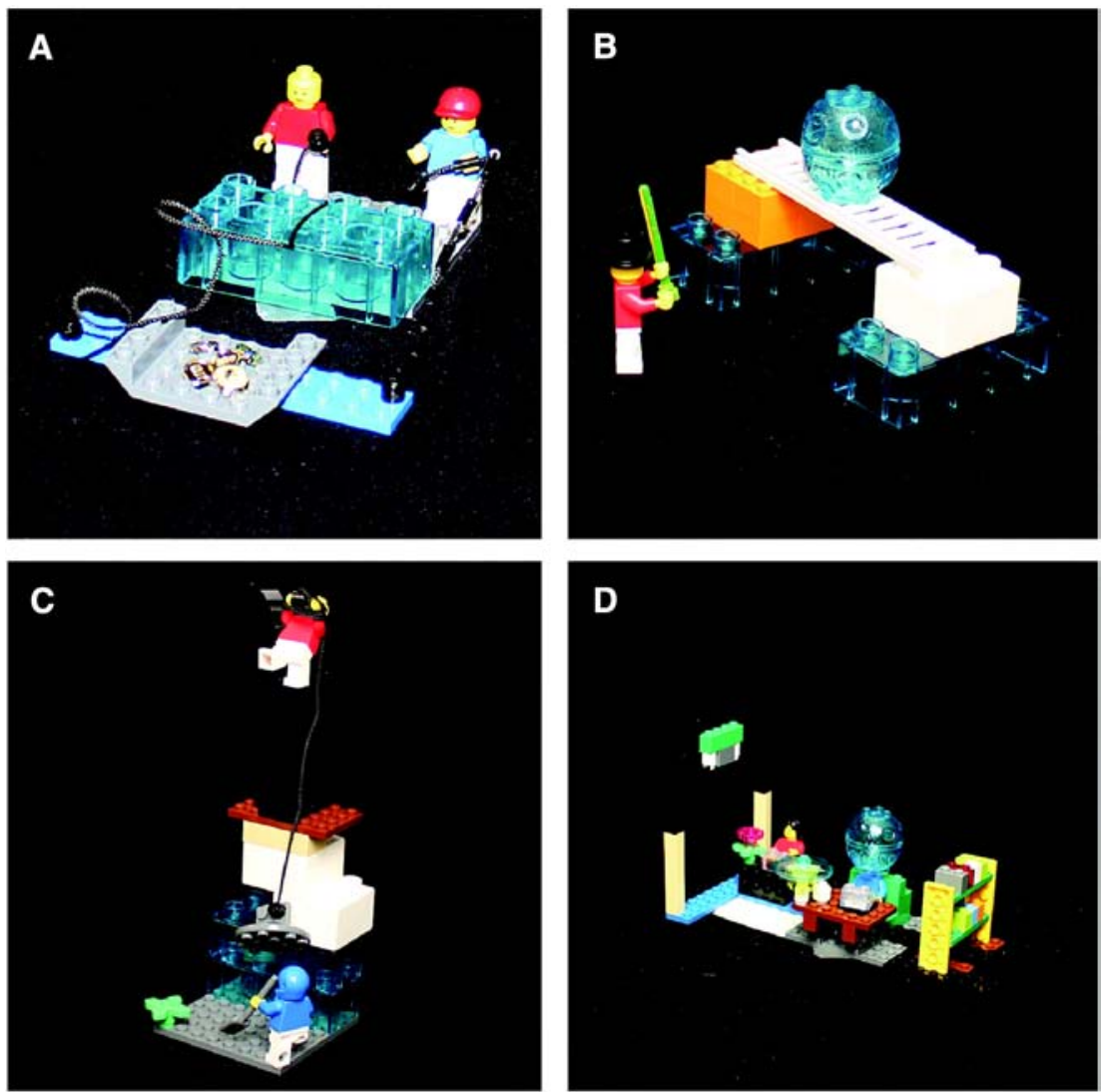

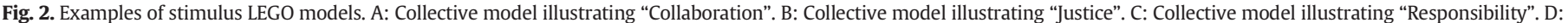
Collective model illustrating "Knowledge".

In the meaning related task, participants would first see a prompt (1.5 s) indicating that they would be subjected to a meaning related task followed by a fixation cross ( $1 \mathrm{~s}$ ). Thereafter they would see one of the six target concepts ('responsibility', 'safety' etc.) written on the screen ( $2 \mathrm{~s})$, then a fixation cross ( $1 \mathrm{~s})$, followed by an image of a LEGO models depicting this target concept $(3 \mathrm{~s})$. After a fixation cross with a random jitter of 3-5 s, participants would be prompted to rate the model on a 6-point scale from "not well" to "very well" in response to the question "How well do you think this model represents the concept X?" After submitting their response, participants would see a fixation cross with a random jitter of 3-5 s before they proceeded to the next trial. If participants failed to submit their response within $5 \mathrm{~s}$, it would time-out and they would proceed to the next trial (see Fig. 3A).

In the physical property related task, participants would first see a prompt indicating that they would be subjected to a physical property task $(1.5 \mathrm{~s})$ followed by a fixation cross $(1 \mathrm{~s})$. Then they would be presented with an image of one of the LEGO models from one of the four conditions ( $3 \mathrm{~s}$ ). After a fixation cross (random jitter 3-5s), they were prompted to rate the model on a 6 point scale from "fragile" to "robust" in response to the question "How fragile/robust do you find this model?" Like in the meaning related task the trial would proceed with the participant's submission or time-out after $5 \mathrm{~s}$ (see Fig. 3B).

In both types of rating tasks, participants performed their rating by moving a cursor to the desired value on the rating scale by tapping a response box button with the right hand index finger and then submit the decision using the right-hand middle finger.

All LEGO models were presented twice from two different perspectives in a randomized order through 96 trials ( 48 belonging to the meaning and 48 to the physical rating condition). Stimulus presentation and response recording were carried out using Cogent 2000 for MATLAB (Mathworks Inc. Sherborn, MA).

\section{fMRI acquisition parameters and analysis}

We used a 3 T Siemens TIM Trio MRI system with a 12 channel head coil to acquire the $\mathrm{T} 2 *$ weighted gradient echo, echo-planar images (EPI) with Blood Oxygenation Level-Dependent (BOLD) contrast using the following parameters: echo time (TE): $30 \mathrm{~ms}$, repetition time (TR): $3000 \mathrm{~ms}$, and a flip angle of $90^{\circ}$. Six hundred twenty wholebrain images were obtained over fifty-six sequential, interleaved $2.5 \mathrm{~mm}$ axial slices with a $3 \times 3 \mathrm{~mm}$ resolution and a field of view of $192 \times 192 \mathrm{~mm}$ in one scanning session lasting approx. $25 \mathrm{~min}$.

All fMRI data analyses were conducted using SPM8 (Statistical Parametric Mapping, Wellcome Department of Imaging Neuroscience, London) implemented in MATLAB R2013b using default settings unless otherwise specified. Images were spatially realigned, normalized to the MNI template and smoothed with an isotropic $8 \mathrm{~mm}$ FWHM Gaussian kernel. Statistical analysis was conducted following a two-level general linear model approach (Penny and Holmes, 2007). On the first-level, single participant task-related BOLD responses were modeled for each subject by convolving condition onsets and durations with the standard hemodynamic response function, and effects for each condition were estimated using a general linear model approach. Only responses to the stimulus presentation itself (images of LEGO models) were explicitly modeled in the fMRI analysis. The main contrast concerned perception of the LEGO models in the meaning-related versus the physical property-related task. Then, for the meaning related task, main and interaction effects of the four conditions were modeled. Besides the analysis included standard regressors for the six SPM8 motion parameters and a high-pass filter set to $128 \mathrm{~s}$ cut off. Contrast images from the first-level analysis went into a second-level, random effects group analysis using the one-sample $t$-tests in SPM8. The significance threshold for all main effects was set to $p<.05$, FDR corrected for multiple 
A Meaning-related task

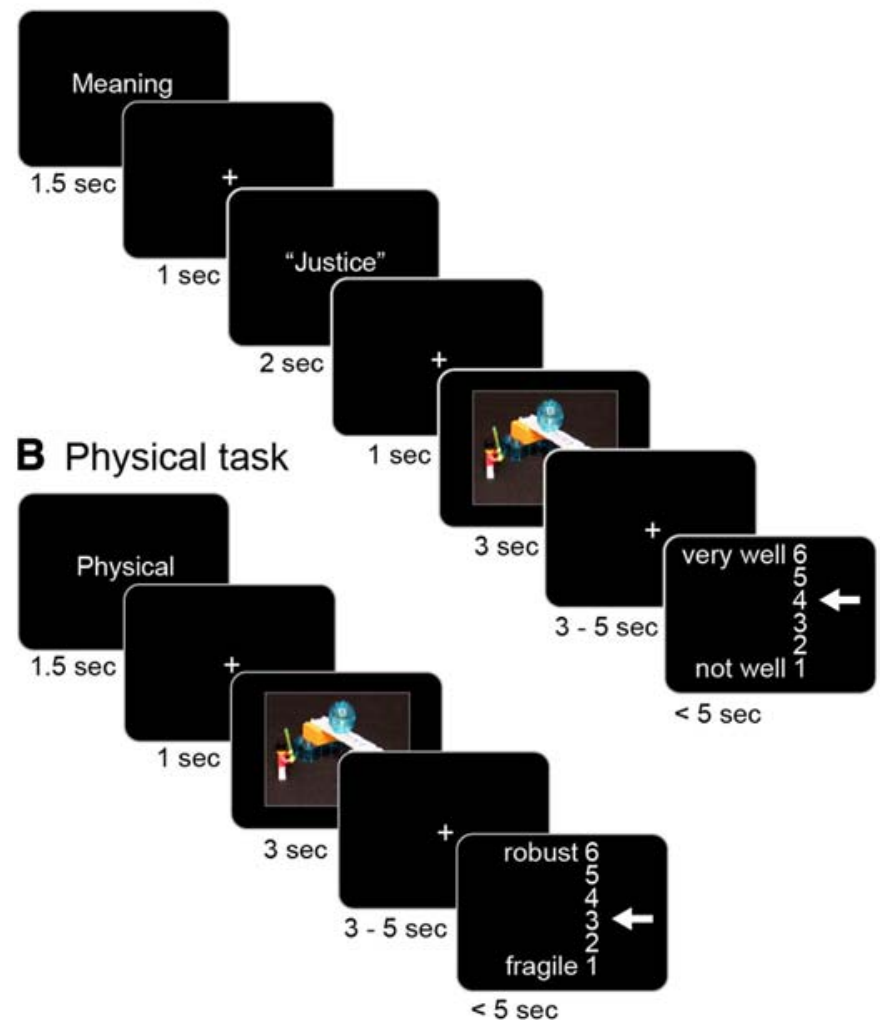

Fig. 3. Schematic representation of the in-scanner experimental tasks. A: Sequential structure of the meaning-related task. B: Sequential structure of the physical property task.

comparisons. The reported interaction effects were masked with the main effect of the meaning-related task using the small volume correction function in SPM, thresholded at $p<.01$, FEW corrected for multiple comparisons. All corrections were carried out at the peak voxel level following the recommendations of Friston et al. (1995). Functional images were overlaid with the standard SPM8 single subject high resolution T1 image.

While the preceding analyses among other things test for effects of seeing one's own versus other's models, we were also interested in whether particular qualities of the collaboration with fellow group members would modulate brain activity in response to own collective models. In order to assess if individual differences in participants' experiences of interaction predicted variability in brain responses to the LEGO models, we conducted an analysis testing participants' self-reported ratings of relatedness and group competence against their brain activity in the interaction effect (collective $>$ individual $*$ own $>$ other). This was done by explorative plotting the peak contrast estimates from the interaction effect as a function of individual ratings of relatedness and group competence implemented as user specified ordinates in SPM8. Since the ratings were not normally distributed, the relations were assessed using Spearman's rank correlation rho calculated in $R$ 3.2. (RStudio Team, 2015).

\section{Results}

\section{fMRI results}

Contrasting the 'meaning' > 'physical property' related task yielded patterns of activation in a bilateral network of brain areas comprising mainly the dorso-medial PFC, TPJ, and inferior frontal gyrus (see Table $1 \mathrm{~A}$ for peak voxels and stats and Fig. 4A). The opposite contrast, 'physical property' > 'meaning' related task, yielded activations in the
Table 1

Anatomical regions and coordinates.

\begin{tabular}{|c|c|c|c|c|c|c|c|c|}
\hline \multirow[t]{3}{*}{ Anatomical site } & \multicolumn{4}{|c|}{ Left hemisphere } & \multicolumn{4}{|c|}{ Right hemisphere } \\
\hline & \multirow[t]{2}{*}{ Z-score } & \multicolumn{3}{|c|}{ MNI coordinates } & \multirow[t]{2}{*}{ Z-score } & \multicolumn{3}{|c|}{ MNI coordinates } \\
\hline & & $\mathrm{x}$ & $\mathrm{y}$ & $\mathrm{z}$ & & $\mathrm{x}$ & $\mathrm{y}$ & $\mathrm{z}$ \\
\hline \multicolumn{9}{|c|}{ A Meaning > Physical } \\
\hline Dorsal mPFC & 8.04 & -14 & 48 & 44 & 7.47 & 10 & 48 & 42 \\
\hline TPJ & 7.58 & -46 & -60 & 28 & 6.18 & 50 & -68 & 36 \\
\hline IFG & 5.95 & -52 & 28 & -8 & 7.52 & 52 & 30 & -12 \\
\hline Postcentral gyrus & 6.05 & -34 & -24 & 48 & - & - & - & - \\
\hline Temporal pole & - & - & - & - & 4.32 & 42 & 5 & -44 \\
\hline \multicolumn{9}{|c|}{ B Physical > Meaning } \\
\hline Precentral gyrus & - & - & - & - & 7.94 & 52 & -14 & 58 \\
\hline Fusiform gyrus & 6.39 & -24 & -54 & -14 & 6.67 & 28 & -56 & -12 \\
\hline Paracentral lobule & - & - & - & - & 4.40 & 2 & -32 & 56 \\
\hline Primary occipital & 4.91 & -14 & -88 & -10 & 3.79 & 18 & -86 & -8 \\
\hline \multicolumn{9}{|c|}{ C Own $>$ Other (meaning related task) } \\
\hline $\mathrm{mPFC}$ & - & - & - & - & 7.69 & 10 & 56 & 4 \\
\hline Rostral ACC & 6.99 & 4 & 32 & 10 & - & - & - & - \\
\hline TPJ & 6.33 & -44 & -58 & 40 & - & - & - & - \\
\hline Precuneus & 6.12 & -8 & -56 & 18 & - & - & - & - \\
\hline \multicolumn{9}{|c|}{ D Own $>$ Other $\times$ Collective $>$ Individual $(\text { meaning related task })^{*}$} \\
\hline Rostral ACC & 5.53 & -2 & 38 & 2 & - & - & - & - \\
\hline IFG & - & - & - & - & 4.73 & 50 & 12 & 8 \\
\hline Insula & 4.54 & -35 & 12 & -8 & - & - & - & - \\
\hline
\end{tabular}

right precentral gyrus, the fusiform gyrus bilaterally, and the primary occipital cortex bilaterally (Table 1B and Fig. 4B). The four factorial conditions were tested separately for the two tasks. For the meaning related task, the contrast 'own' > 'other' activated the right medial prefrontal and anterior cingulate cortex, left TPJ and precuneus (see Table 1C and Fig. 4C). The opposite contrast, 'other $>$ own' and both main effects of collective/individual did not yield above threshold results, however the interaction 'own' > 'other' $\times$ 'collective' > 'individual' activated a network comprising left anterior cingulate cortex, right inferior frontal gyrus and left insula (see Table 1D and Fig. 5a). Explorative plotting of contrast estimates in the global peak voxel (rostral ACC) suggests that the interaction effect is driven primarily by the activation caused by participation in collective LEGO constructions (see Fig. 5b).

Analyzing the relation between participants' subjective assessments of the collaboration and the brain activity during the meaning related task showed that variability in left insula was significantly predicted by the feeling of relatedness to fellow group members, $r_{s}(23)=0.43$, $R^{2}=0.19, p<0.05$ (see Fig. $5 c$ ). No other above threshold effects was found.

\section{Discussion}

We found differential patterns of brain activation when participants were primed to perceive LEGO models as physical constructs (rating their fragility) and when they approached them as vehicles of socially constituted meaning (rating their meaning potentials). Rating the fragility of a LEGO model calls special attention to its physical surface structure and might imply imagining to haptically manipulate it. Correspondingly, we found the fusiform gyrus bilaterally and areas of right pre-central gyrus to be activated in this task. Both sites have previously been found related to perception of physical objects (Shmuelof and Zohary, 2005). While the fusiform gyrus is mostly associated with object recognition and categorization (Bar et al., 2001; Chao et al., 1999; Gauthier et al., 1999; Grill-Spector, 2003; Whitehead et al., 2009), motor areas have been related to mental object manipulation (Vanrie et al., 2002).

In contrast, rating the meaning potentials of the models requires participants to pay special attention to the expressive qualities of the models, which implies recalling the particular social practices in which 

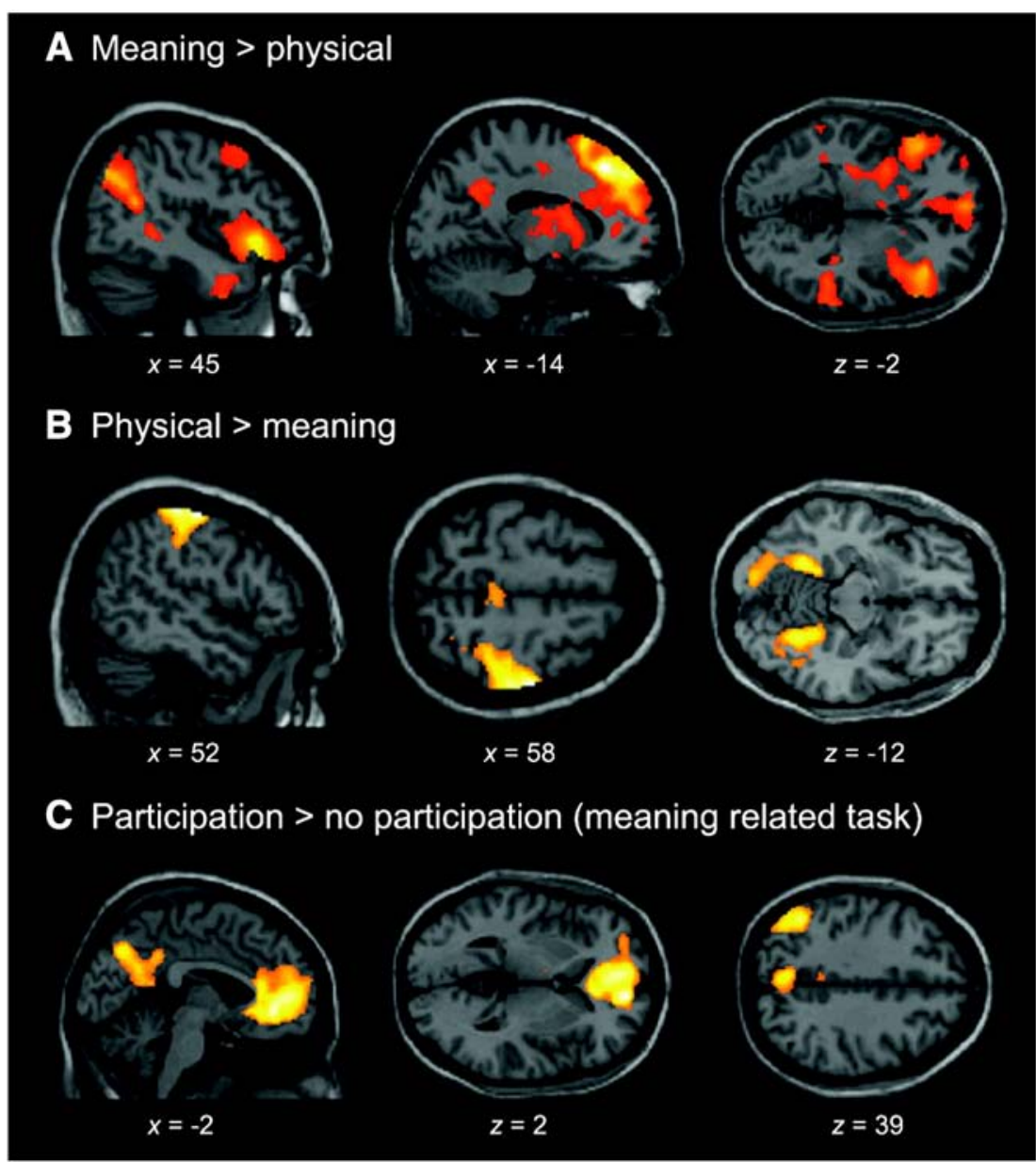

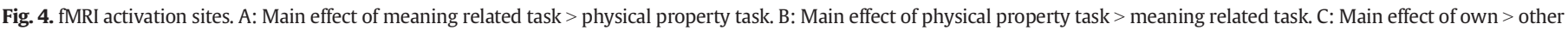
(meaning related task). All contrast are thresholded at $p<.05$ FDR corrected for multiple comparisons.

these meanings evolved, and reading the models as communicative symbols (not unlike gestures, figurative signs or even words). This task was found to activate a bilateral network of areas comprising dorso-medial prefrontal cortex, temporal pole, TPJ and IFG. The MPFC and TPJ are consistently found in studies of social cognition and interaction, and generally associated with mentalizing, agency, and ascription of intentionality (Amodio and Frith, 2006; Frith and Frith, 2006a; Iacoboni et al., 2004; Van Overwalle, 2009). Interestingly, previous studies have claimed mPFC to only activate when participants make judgments about other people and not objects (Mitchell et al., 2002, 2005). We suggest that the meaning-related rating task directed participants' attention to semantic dimensions of the stimulus models constituted by their particular social history and that this gave rise to the activation patterns in mPFC and TPJ (Gallagher et al., 2000; Mano et al., 2011; Saxe and Kanwisher, 2003; Schaefer and Rotte, 2010). Similar effects have been observed in a study of pretense play (Whitehead et al., 2009). Here participants saw actors using objects in canonical ways (for instance using a tennis racket to hit a ball) and in sequences of pretense play (using the tennis racket as a banjo). When later prompted to name the pretend objects participants showed activations in MPFC, suggesting that these locally constituted meanings of the object relied more on areas sensitive to social intentions. Our findings are also consistent with Baetens et al.'s suggestion that the dorso-medial prefrontal cortex (dmPFC) is involved with so-called 'high construal' of both social (persons) and non-social (objects) stimuli (Baetens et al., 2013, 2015). High construal involves selective focus on a few essential properties of a stimulus to infer properties (traits, category-membership etc.) that are not part of the direct perceptual experience of the stimulus. In other words, we infer more abstract type-membership from presentations of concrete tokens. Baetens et al. even speculate that high construal more generally reflects the 'meaning' of the stimuli, as opposed to their individual properties. This corresponds to our finding that the dmPFC is selectively activated when the LEGO models are appreciated for their meaning in contrast to their bare physical properties.

We also found activations of the IFG bilaterally and the right temporal pole. IFG, particularly in the left hemisphere, is traditionally considered a "language area" and consistently shows up in studies on verbal semantics (Newman et al., 2001, 2003; Rodd et al., 2005). However, recent studies suggest generalizing the function of IFG to semantic aspects of other modalities of communication and expressivity as well. For instance, the IFG has been found in studies of hand gestures (Dick et al., 2009; Xu et al., 2009), facial expressions (Jabbi and Keysers, 2008), music (Vuust et al., 2005), as well as studies on symbolic objects (Tylén et al., 2009). It is often noticed that in case of non-verbal (or complex verbal) stimuli, bilateral activation patterns are more prevalent, suggesting higher processing demands due to differential levels of complexity, conventionalization or expertise (Tylén et al., 2009; Vuust et al., 2005; Yang et al., 2009). The temporal poles are also often related to aspects of verbal semantics (Kumfor et al., 2016; Price, 2010). While most studies report left temporal pole activity, some studies suggest a special role for the right homolog in relation to more figurative and pragmatic aspects of meaning (Diaz et al., 2011; Diaz and Hogstrom, 2011). We suggest that the activation of IFG in this experiment is related to the way participants explore the LEGO models to make assessments of their meaning potentials (rather than their mere physical attributes). This involves reading the models as communicative signs not unlike 


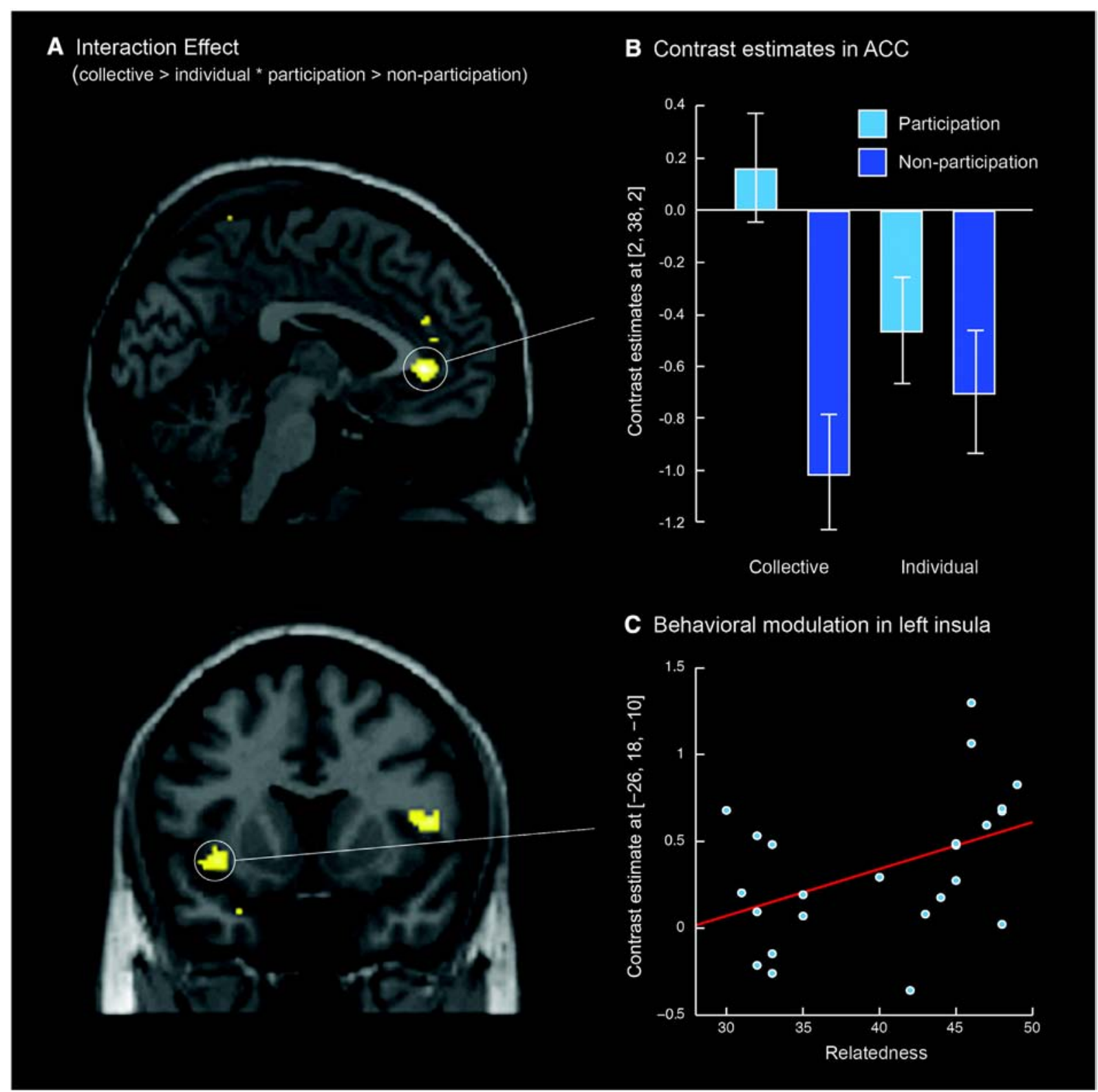

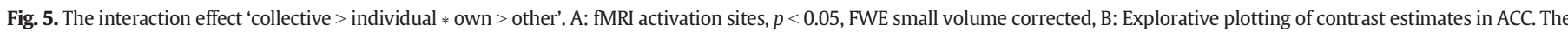

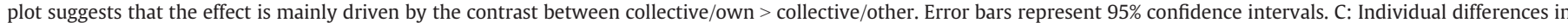

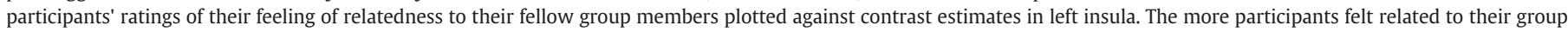
members, the stronger the activation of insula.

verbal or gestural signals (Tylén et al., 2011). The involvement of the right temporal pole might be related to the fact that the models often would represent their abstract target concepts in a figurative or metaphoric fashion.

In the meaning-related condition, we found a strong main effect of participation - that is - seeing models that the participant had constructed herself individually or with her group in contrast to models built by other individuals/groups. Making assessments of your own collective and individual models may depend more on episodic memory traces: the participant's judgments of the meaning related properties of the models rely in part on personal recollections of the preceding building activities and discussions and perhaps though to a lesser extent on semantic memory and processing. Accordingly, this contrast yielded activation in social cognition areas such as MPFC, anterior cingulate, and left TPJ. This replicates findings from previous studies investigating the contrast between self-generated and other generated texts (Mano et al., 2011) and studies of the extended self (perceiving own versus others' objects, Kim and Johnson, 2014). Interestingly, we do not find the meaning-related pattern of IFG activation in this contrast, which suggests that IFG is involved in more general explorations of meaning across own and others' models. However, we observed additional activations of left precuneus, an area consistently found in studies of autobiographical memory and experience of agency (Cavanna and Trimble, 2006; Maddock et al., 2001).

We did not observe a main effect of collective > individual models, which is unsurprising due to the fact that this distinction was hard to discern in half of the cases, those belonging to the 'other' condition. However, the collective versus individual factor interacts significantly with the own versus other factor: When participants made assessments of their own collective models (in contrast to other's/individual), we found activation in the anterior cingulate, the right IFG and the left insula. Explorative plotting of contrast estimates (see Fig. 5b) suggests that this effect is mainly driven by the own-other contrast within collective LEGO constructions, while contrasting individual models did not 
evoke strong differences. The insula is interesting in this respect as it is often associated with social emotions (Phan et al., 2002) and empathy (Singer, 2006; Singer and Lamm, 2009). Furthermore, it has been suggested that the insula forms a network with the anterior cingulate cortex sensitive to the saliency of stimuli and events (Menon and Uddin, 2010). It is likely that the more arousing character of collective building activities (in contrast to individual building activities) might make these models more salient to the participant and thus evoke stronger insula and anterior cingulate activations (Fusaroli et al., in press). This is further supported by the finding that variability in left insula activity is significantly predicted by individual differences in the feeling of relatedness to fellow group members as assessed right after the LEGO construction activities through the Intrinsic Motivation Inventory (Ryan, 1982). The stronger the participants rate their relations to fellow members of the group, the higher the contrast estimates in insula suggesting that insula activity is related especially to the socially emotional history of the models.

Together, our findings show how our perception of even static, material objects can activate the brain areas traditionally thought to be involved only in perception of social behaviors, intentionality ascription and mentalizing. This happens when the objects are designed and recruited as vehicles of socially constituted meaning through local cultural practices. The findings thus support a view according to which human social life extends far beyond face-to-face interactions. We actively construct, exchange, and otherwise surround ourselves with material structures richly imbued with social meaning. In this fashion, human interactions establish, maintain and develop composite neuro-cognitive trails in our minds and environments. These persistent cognitive trails enable evolutionarily unprecedented socio-cultural complexity, accumulation and exchange. Our study thus contributes to discussions of the articulated nature of human socio-cultural cognition and in particular the hybrid nature of symbolic artifacts - as simultaneously material (LEGO models) and neurocognitive trails of social interactions and practices (Hutchins, 2008; Tylén et al., 2009).

\section{Conclusions}

In this study we investigated the neurocognitive status of symbolic artifacts. Together our findings support the idea that symbolic artifacts are simultaneously physical objects and vehicles for non-tangible social meanings. Very different neurocognitive processes are involved in attending to physical features and social meanings, and in the latter case they are modulated by a history of social engagement of the object. Symbolic artifacts might thus be conceived as material and neurocognitive trails of social interactions and cultural meanings.

\section{Acknowledgments}

The authors would like to thank Bo Stjerne Thomsen, Robert Rasmussen, Linda Post, Peer Christensen and the LEGO foundation. This research was supported by the Danish Council for Independent Research's project Joint Diagrammatical Reasoning in Language (grant number 0602-01756B), the Interacting Minds Centre (Aarhus University), the EU Marie Currie ITN network Towards an Embodied Science of Intersubjectivity, TESIS and the ESF project Digging for the Roots of Understanding, DRUST.

\section{References}

Amodio, D., Frith, C., 2006. Meeting of minds: the medial frontal cortex and social cognition. Nat. Rev. Neurosci. 7, 268-277.

Baetens, K., Ma, N., Steen, J., Van Overwalle, F., 2013. Involvement of the mentalizing network in social and non-social high construal. Soc. Cogn. Affect. Neurosci. nst048.

Baetens, K., Vandekerckhove, M., Van Overwalle, F., 2015. Social versus nonsocial reasoning. In: Toga, A. (Ed.), Brain Mapping: An Encyclopedic Reference. Elsevier, pp. 227-230.
Bar, M., Tootell, R.B., Schacter, D.L., Greve, D.N., Fischl, B., Mendola, J.D., Rosen, B.R., Dale, A.M., 2001. Cortical mechanisms specific to explicit visual object recognition. Neuron 29, 529-535

Binkofski, F., Buccino, G., Posse, S., Seitz, R.J., Rizzolatti, G., Freund, H.J., 1999. A frontoparietal circuit for object manipulation in man: evidence from an fMRI-study. Eur. J. Neurosci. 11, 3276-3286.

Bjørndahl, J., Fusaroli, R., Østergaard, S., Tylén, K., 2014. Thinking together with material representations: joint epistemic actions in creative problem solving. Cogn. Semiot. 7, 103-123.

Bjørndahl, J., Fusaroli, R., Østergaard, S., Tylén, K., 2015. When agreeing is not enough. Interact. Stud. 16.

Caramazza, A., Shelton, J., 1998. Domain-specific knowledge systems in the brain: the animate-inanimate distinction. J. Cogn. Neurosci. 10, 1-34.

Cavanna, A.E., Trimble, M.R., 2006. The precuneus: a review of its functional anatomy and behavioural correlates. Brain 129, 564-583.

Chao, L.L., Haxby, J.V., Martin, A., 1999. Attribute-based neural substrates in temporal cortex for perceiving and knowing about objects. Nat. Neurosci. 2, 913-919.

Clark, A., 2006. Material symbols. Philos. Psychol. 19, 291-307.

Cussins, A., 1992. Content, embodiment and objectivity: the theory of cognitive trails. Mind 101, 651

Diaz, M.T., Hogstrom, L.J., 2011. The influence of context on hemispheric recruitment during metaphor processing. J. Cogn. Neurosci. 23, 3586-3597.

Diaz, M.T., Barrett, K.T., Hogstrom, L.J., 2011. The influence of sentence novelty and figurativeness on brain activity. Neuropsychologia 49, 320-330.

Dick, A.S., Goldin-Meadow, S., Hasson, U., Skipper, J.I., Small, S.L., 2009. Co-speech gestures influence neural activity in brain regions associated with processing semantic information. Hum. Brain Mapp. 30, 3509-3526.

Friston, K.J., Ashburner, J., Poline, J.B., Frith, C.D., Heather, J.D., Frackowiak, R.S., 1995. Spatial registration and normalization of images Hum. Brain Mapp. 165-189.

Frith, C.D., 2007. The social brain? Philos. Trans. R. Soc. B Biol. Sci. 362, 671-678.

Frith, C., Frith, U., 2006a. The neural basis of mentalizing. Neuron 50, 531-534.

Frith, C.D., Frith, U., 2006b. The neural basis of mentalizing. Neuron 50, 531-534.

Fusaroli, R., Bjørndahl, J.S., Roepstorff, A., Tylen, K., 2016. A heart for interaction: shared physiological dynamics and behavioral coordination in a collective creative construction task. J. Exp. Psychol. Hum. Percept. Perform. http://dx.doi.org/10.1037/ xhp0000207 (in press).

Galantucci, B., 2005. An experimental study of the emergence of human communication systems. Cogn. Sci. 29, 737-767.

Gallagher, H.L., Happé, F., Brunswick, N., Fletcher, P.C., Frith, U., Frith, C.D., 2000. Reading the mind in cartoons and stories: an fMRI study of 'theory of mind' in verbal and nonverbal tasks. Neuropsychologia 38, 11-21.

Garrod, S., Fay, N., Lee, J., Oberlander, J., MacLeod, T., 2007. Foundations of representation: where might graphical symbol systems come from? Cogn. Sci. 31, 961-987

Gauthier, I., Tarr, M.J., Anderson, A.W., Skudlarski, P., Gore, J.C., 1999. Activation of the middle fusiform'face area'increases with expertise in recognizing novel objects. Nat. Neurosci. 2, 568-573.

Gobbini, M.I., Gentili, C., Ricciardi, E., Bellucci, C., Salvini, P., Laschi, C., Guazzelli, M., Pietrini, P., 2011. Distinct neural systems involved in agency and animacy detection. J. Cogn. Neurosci. 23, 1911-1920.

Grill-Spector, K., 2003. The neural basis of object perception. Curr. Opin. Neurobiol. 13, 159-166.

Hagoort, P., 2005. On Broca, brain, and binding: a new framework. Trends Cogn. Sci. 9, 416-423.

Hutchins, E., 2005. Material anchors for conceptual blends. J. Pragmat. 37, 1555-1577.

Hutchins, E., 2008. The role of cultural practices in the emergence of modern human intelligence. Philos. Trans. R. Soc. Lond. B Biol. Sci. 363, 2011-2019.

Iacoboni, M., Lieberman, M.D., Knowlton, B.J., Molnar-Szakacs, I., Moritz, M., Throop, C.J., Fiske, A.P., 2004. Watching social interactions produces dorsomedial prefrontal and medial parietal BOLD fMRI signal increases compared to a resting baseline. Neurolmage 21, 1167-1173.

Jabbi, M., Keysers, C., 2008. Inferior frontal gyrus activity triggers anterior insula response to emotional facial expressions. Emotion 8, 775-780.

Jack, A.I., Dawson, A.J., Begany, K.L., Leckie, R.L., Barry, K.P., Ciccia, A.H., Snyder, A.Z., 2013. fMRI reveals reciprocal inhibition between social and physical cognitive domains. Neurolmage 66, 385-401.

Jung-Beeman, M., 2005. Bilateral brain processes for comprehending natural language. Trends Cogn. Sci. 9, 512-518.

Kim, K., Johnson, M.K., 2014. Extended self: spontaneous activation of medial prefrontal cortex by objects that are 'mine'. Soc. Cogn. Affect. Neurosci. 9, 1006-1012.

Kumfor, F., Landin-Romero, R., Devenney, E., Hutchings, R., Grasso, R., Hodges, J.R., Piguet, O., 2016. On the right side? A longitudinal study of left-versus right-lateralized semantic dementia. Brain awv387.

Laland, K.N., Odling-Smee, J., Feldman, M.W., 2000. Niche construction, biological evolution, and cultural change. Behav. Brain Sci. 23, 131-146.

Latour, B., 1996. On interobjectivity. Mind Cult. Act. 3, 228-245.

Latour, B., 2000. The Berlin Key or How to do Words With Things. Matter, Materiality and Modern Culture. Routledge, London, pp. 10-21.

Leslie, A.M., 1987. Pretense and representation: the origins of "theory of mind". Psychol. Rev. 94, 412-426.

Lieberman, M.D., 2007. Social cognitive neuroscience: a review of core processes. Annu. Rev. Psychol. 58, 259-289.

Maddock, R.J., Garrett, A.S., Buonocore, M.H., 2001. Remembering familiar people: the posterior cingulate cortex and autobiographical memory retrieval. Neuroscience 104, 667-676. 
Mano, Y., Sugiura, M., Tsukiura, T., Chiao, J.Y., Yomogida, Y., Jeong, H., Sekiguchi, A, Kawashima, R., 2011. The representation of social interaction in episodic memory: a functional MRI study. NeuroImage 57, 1234-1242.

Menon, V., Uddin, L.Q., 2010. Saliency, switching, attention and control: a network model of insula function. Brain Struct. Funct. 214, 655-667.

Mitchell, J.P., Heatherton, T.F., Macrae, C.N., 2002. Distinct neural systems subserve person and object knowledge. Proc. Natl. Acad. Sci. U. S. A. 99, 15238-15243.

Mitchell, J.P., Neil Macrae, C., Banaji, M.R., 2005. Forming impressions of people versus inanimate objects: social-cognitive processing in the medial prefrontal cortex. Neurolmage 26, 251-257.

Naselaris, T., Stansbury, D.E., Gallant, J.L., 2012. Cortical representation of animate and inanimate objects in complex natural scenes. J. Physiol. Paris 106, 239-249.

Newman, S.D., Just, M.A., Keller, T.A., Roth, J., Carpenter, P.A., 2003. Differential effects of syntactic and semantic processing on the subregions of Broca's area. Brain Res. Cogn. Brain Res. 16, 297-307.

Newman, A.J., Pancheva, R., Ozawa, K., Neville, H.J., Ullman, M.T., 2001. An event-related fMRI study of syntactic and semantic violations. J. Psycholinguist. Res. 30, 339-364.

Penny, W., Holmes, A.P., 2007. Random effects analysis. In: Friston, K.J., Ashburner, J., Kiebel, S., Nichols, T., Penny, W. (Eds.), Statistical Parametric Mapping: The Analysis of Functional Brain Images. Academic Press, London.

Phan, K.L., Wager, T., Taylor, S.F., Liberzon, I., 2002. Functional neuroanatomy of emotion: a meta-analysis of emotion activation studies in PET and fMRI. NeuroImage 16, 331-348.

Price, C.J., 2010. The anatomy of language: a review of $100 \mathrm{fMRI}$ studies published in 2009. Ann. N. Y. Acad. Sci. 1191, 62-88.

Rodd, J.M., Davis, M.H., Johnsrude, I.S., 2005. The neural mechanisms of speech comprehension: fMRI studies of semantic ambiguity. Cereb. Cortex 15, 1261-1269.

Roepstorff, A., 2008. Things to think with: words and objects as material symbols. Philos. Trans. R. Soc. B Biol. Sci. 363, 2049-2054.

RStudio Team, 2015. RStudio. Integrated Development for R. RStudio, Inc., Boston, MA.

Ryan, R.M., 1982. Control and information in the intrapersonal sphere: an extension of cognitive evaluation theory. J. Pers. Soc. Psychol. 43, 450.

Saxe, R., Kanwisher, N., 2003. People thinking about thinking people: the role of the temporo-parietal junction in "theory of mind". Neurolmage 19, 1835-1842.

Schaefer, M., Rotte, M., 2010. Combining a semantic differential with fMRI to investigate brands as cultural symbols. Soc. Cogn. Affect. Neurosci. 5, 274-281.

Shmuelof, L., Zohary, E., 2005. Dissociation between ventral and dorsal fMRI activation during object and action recognition. Neuron 47, 457-470.

Singer, T., 2006. The neuronal basis and ontogeny of empathy and mind reading: review of literature and implications for future research. Neurosci. Biobehav. Rev. 30, $855-863$.

Singer, T., Lamm, C., 2009. The social neuroscience of empathy. Ann. N. Y. Acad. Sci. 1156, 81-96.

Spunt, R.P., Adolphs, R., 2014. Validating the why/how contrast for functional MRI studies of theory of mind. Neurolmage $99,301-311$.
Spunt, R.P., Lieberman, M.D., 2012. Dissociating modality-specific and supramodal neural systems for action understanding. J. Neurosci. 32, 3575-3583.

Spunt, R.P., Lieberman, M.D., 2014. Automaticity, control, and the social brain. In: Sherman, J.W., Gawronski, B., Trope, Y. (Eds.), Dual-Process Theories of the Social Mind. Guilford, p. 279.

Spunt, R.P., Falk, E.B., Lieberman, M.D., 2010. Dissociable neural systems support retrieval of how and why action knowledge. Psychol. Sci. 21, 1593-1598.

Spunt, R.P., Satpute, A.B., Lieberman, M.D., 2011. Identifying the what, why, and how of an observed action: an fMRI study of mentalizing and mechanizing during action observation. J. Cogn. Neurosci. 23, 63-74.

Tylén, K., Allen, M., Hunter, B.K., Roepstorff, A., 2012. Interaction vs. observation: distinctive modes of social cognition in human brain and behavior? A combined fMRI and eye-tracking study. Front. Hum. Neurosci. 6, 331.

Tylén, K., Bjørndahl, J.S., Weed, E., 2011. Actualizing semiotic affordances in a materia world. Benjamins Curr. Top. 81.

Tylén, K., Fusaroli, R., Bundgaard, P.F., Østergaard, S., 2013. Making sense together: a dynamical account of linguistic meaning-making. Semiotica 2013, 39-62.

Tylén, K., Wallentin, M., Roepstorff, A., 2009. Say it with flowers! An fMRI study of object mediated communication. Brain Lang. 108, 159-166.

Van Overwalle, F., 2009. Social cognition and the brain: a meta-analysis. Hum. Brain Mapp. 30, 829-858.

Vanrie, J., Beatse, E., Wagemans, J., Sunaert, S., Van Hecke, P., 2002. Mental rotation versus invariant features in object perception from different viewpoints: an fMRI study. Neuropsychologia 40, 917-930.

Vuust, P., Pallesen, K., Bailey, C., van Zuijen, T., Gjedde, A., Roepstorff, A., Vòstergaard, L. 2005. To musicians, the message is in the meter pre-attentive neuronal responses to incongruent rhythm are left-lateralized in musicians. Neurolmage 24, 560-564.

Walter, H., Adenzato, M., Ciaramidaro, A., Enrici, I., Pia, L., Bara, B.G., 2004. Understanding intentions in social interaction: the role of the anterior paracingulate cortex. J. Cogn. Neurosci. 16, 1854-1863.

Whitehead, C., Marchant, J.L., Craik, D., Frith, C.D., 2009. Neural correlates of observing pretend play in which one object is represented as another. Soc. Cogn. Affect. Neurosci. 4, 369-378.

Wyman, E., Rakoczy, H., Tomasello, M., 2009. Normativity and context in young children's pretend play. Cogn. Dev. 24, 146-155.

Xu, J., Gannon, P.J., Emmorey, K., Smith, J.F., Braun, A.R., 2009. Symbolic gestures and spoken language are processed by a common neural system. Proc. Natl. Acad. Sci. U. S. A 106, 20664-20669.

Yang, F.G., Edens, J., Simpson, C., Krawczyk, D.C., 2009. Differences in task demands influence the hemispheric lateralization and neural correlates of metaphor. Brain Lang. $111,114-124$. 